\title{
Dilemas e desafios da formação profissional em saúde
}

\author{
The dilemmas and challenges of professional training in health

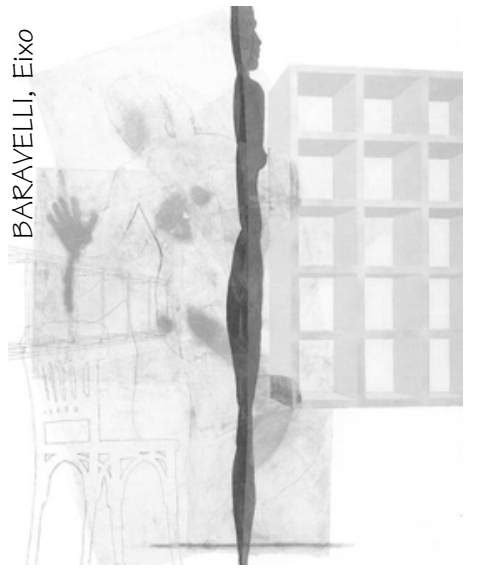 \\ Antenor Amâncio Filho ${ }^{1}$

\section{O contexto} \\ Vive-se hoje, no país, um raro momento histórico. Passada a euforia das eleições para Presidente da \\ República, governadores e ocupantes de cargos nas esferas legislativas federal (Senado e Câmara) e \\ estadual (Assembléias), a sociedade brasileira vivencia uma dupla ansiedade: uma certa apreensão quanto \\ à possibilidade de reconfigurar o modelo de país construído até agora e a expectativa em relação à \\ implementação de medidas que objetivem mudanças nas políticas públicas (com destaque para as \\ econômicas e sociais), adotadas e defendidas pela administração que se encerrou no último dia de \\ dezembro de 2002. \\ Para isto, vem sendo estabelecida pelo governo e exposta para a sociedade, conclamada para debatê- \\ la, uma agenda de ações tidas como prioritárias (como as reformas no sistema previdenciário, nas áreas \\ tributária e fiscal, na educação, na segurança pública, na saúde), para que transformações requeridas pela \\ sociedade venham a ocorrer de maneira segura e irreversível, viabilizando uma vigorosa mudança no \\ enfoque e na determinação das políticas públicas. \\ Nesse contexto em que se insinua a busca por um novo sentido para a vida, em que sobressaiam o \\ respeito à dignidade humana e a defesa intransigente dos direitos de cidadania, o trato e o destino da coisa \\ pública vêm constituindo, cada vez mais, assunto inquietante, em particular para as forças políticas que \\ defendem um Estado estruturado para distribuir riquezas e promover a justiça social. O discurso e as \\ ações de caráter neoliberal, predominante na maior parte dos países, procuram expor que, em virtude de \\ uma demasiada interferência do Estado, especialmente na aplicação de recursos para as denominadas \\ áreas sociais (educação, saúde, transporte, habitação), a situação de crise hoje instalada seria fortuita e \\ de aspecto meramente conjuntural e não, como explicita Frigotto (1995, p.62), "um elemento constituinte, \\ estrutural, do movimento cíclico da acumulação capitalista, assumindo formas específicas que variam de \\ intensidade no tempo e no espaço".
}

${ }^{1}$ Pesquisador, Escola Nacional de Saúde Pública Sérgio Arouca/Fundação Oswaldo Cruz, Departamento de Administração e Planejamento em Saúde.<amancio@ensp.fiocruz.br>

Rua Esteves Junior, 22, apto. 101

Laranjeiras - Rio de Janeiro, RJ

22.231-160 
De fato, a expansão do movimento de globalização ${ }^{2}$ vem implicando mudanças econômicas, sociais, políticas e culturais. Para enfrentar a nova divisão internacional do trabalho, políticas de corte neoliberal propõem mudanças em relação ao tamanho e às atribuições do Estado, advogam a desregulamentação das economias nacionais, enfatizam o papel do mercado e adotam um amplo programa de privatizações na esfera pública, incluindo áreas tradicionais de atuação, como educação e saúde, para reduzir os gastos estatais. Nesse percurso, o Estado social, "concebido como solução política para as contradições sociais" (Offe, 1991, p.114) passa a ser objeto de crítica em relação a sua concepção e identidade, com questionamentos crescentes quanto a sua credibilidade e eficiência.

Ademais, com os avanços científicos e tecnológicos ocorrendo em todas as esferas do conhecimento, constituindo vigoroso fator de mudanças nas relações sociais e de produção de bens e de serviços, configura-se uma época em que a tendência é que as aspirações/realizações pessoais se referenciem não mais no plano do trabalho, mas no de consumo - sob o pressuposto de que o ser humano deve encontrar e afirmar sua própria identidade pessoal, elevando-a acima de um pretendido bem-estar coletivo - no qual "os indivíduos se hierarquizam segundo o valor de seus ordenados e tudo aquilo que estes possam comprar como símbolo de diferenciação" (Giannotti, 1995, p.3).

Tendo presente as complexas interrelações que caracterizam o mundo atual, o que se aspira é que o debate para (re)discutir o formato e as possibilidades de uma sociedade diferente da atual, tenha como um dos seus focos principais as contradições observadas na tênue fronteira hoje existente entre as esferas pública e privada que, em algumas situações, nitidamente se confundem. Portanto, esse debate deve ter como horizonte uma sociedade remoldada sobre uma base ética que represente a lógica e a primazia do comum, o coletivo posicionado acima de concessões e de privilégios individuais ou de interesses apenas de determinados estratos sociais.

\section{Interrelações entre a educação e a saúde}

Os setores da educação e da saúde, como parte do setor terciário da economia, integram o conjunto daquelas atividades denominadas serviços de consumo coletivo e sofrem, portanto, os mesmos impactos do processo de ajuste macroestrutural a que o setor industrial vem sendo submetido nas duas últimas décadas: redução de custos, privatizações e terceirizações. No Brasil, de uma maneira geral, as instituições públicas de ambos os setores apresentam um quadro de dificuldades e de carências, com conseqüente retraimento e esvaziamento de suas ações, ocasionado por seguidos impactos de leis, de programas, de projetos referenciados em discursos de universalização do acesso, de melhoria da qualidade dos serviços, de modernização de suas práticas, mas descolados da realidade para a qual vêm sendo formulados.

O trabalho em saúde se caracteriza pelas incertezas decorrentes da indeterminação das demandas, pela descontinuidade e pela disponibilidade para atender a todos os casos, inclusive aqueles excepcionais. Ele guarda algumas especificidades que o impedem de seguir uma lógica rígida, como a racionalidade dos critérios da produção material, sendo difícil sua normalização técnica e a avaliação de sua produtividade.

Na saúde, o denominado Movimento da Reforma Sanitária, que adquiriu impulso e dimensão nacional a partir da metade da década de 1980, procurava interpor-se a decisões/razões de ordem governamental, atuando para explicitar e disseminar a percepção da saúde não como contraposição à doença, mas como resultante de uma totalidade da qual é integrante e na qual interferem múltiplas dimensões do real, incluindo as esferas biológica, histórica, sociológica e tecnológica e, simultaneamente, apontando caminhos para superar uma tradicional característica dos organismos públicos, a do cumprimento a-crítico a determinações das instâncias que os subordinam - muitas delas fundadas na expectativa de obtenção de

2 Sobre "a nova ordem política da globalização" e seus desdobramentos para o futuro do mundo, importante a leitura de Império, Hardt \& Negri., 2001. 
resultados imediatos ou de curtíssimo prazo - e, ainda, procurando romper com a renitente inadequação entre formulações teóricas e a rebeldia do cotidiano.

Mudança estratégica firmada por esse movimento dizia respeito à urgente melhoria dos processos de formação dos profissionais da saúde, com ênfase para os de nível médio, tendo em vista a importância da formação, qualificação, treinamento e atualização de pessoas para atuar não apenas em nível de gerência mas, principalmente, para ocupar posições nos segundo, terceiro, quarto escalões da hierarquia funcional, porque é sobre esse contingente que recai enorme parcela de responsabilidade em sustentar e garantir, técnica e politicamente, a permanência do sistema de saúde. Todavia, decorridos tantos anos e acumuladas seguidas intenções de aproximar as áreas da educação e da saúde,

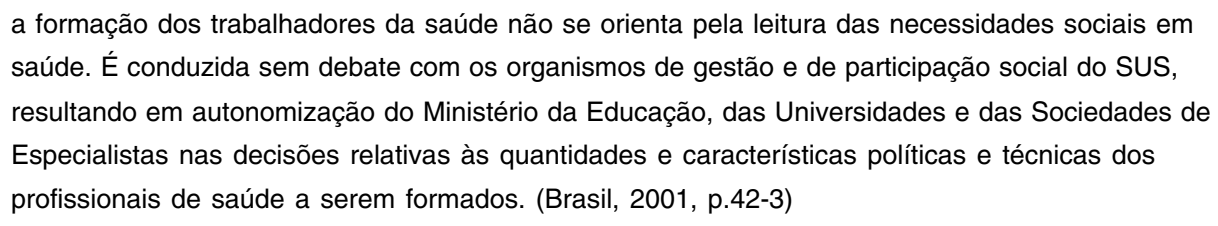

Nas formas legais vigentes, é atribuição do setor educacional aprovar, ministrar e reconhecer habilitações. No entanto, a educação vem formando profissionais para atuar na saúde sem que exista um diagnóstico preciso em relação às necessidades desse setor, o que ocasiona um descompasso entre as ações educacionais e as necessidades dos serviços de saúde, descompasso que obriga o setor saúde a assumir a responsabilidade e a intensificar iniciativas para preparar seus quadros nos próprios locais de trabalho, em particular os de nível médio, seja pela via do ensino supletivo, seja por meio de reciclagens e de treinamentos informais, na medida da incorporação desses profissionais à rede prestadora de serviços ${ }^{3}$.

Mesmo reconhecendo os esforços que vêm sendo efetivados nos últimos anos no tocante à formação de recursos humanos para a saúde, sob o argumento de consolidar o modelo do Sistema Único de Saúde, de uma maneira geral a formação dos trabalhadores desse setor permanece centrada na doença, "fundamentada no paradigma biologicista, tendo como unidade de ação e de reflexão o indivíduo, considerado em sua dimensão anátomo-clínica” (UFRJ/NESC, 2003, p.6), podendo ser observada a ausência ou a insuficiência de conteúdos que possibilitem (re)configurar a saúde como "a resultante das condições de alimentação, habitação, renda, meio ambiente, trabalho, transporte, lazer, acesso e posse da terra e acesso e acesso a serviços de saúde" (Brasil, 1986, p.382), e que inclui, também, a assistência social, a educação, o saneamento. É visível a dificuldade de aplicação prática, por exemplo, de conceitos como o da promoção da saúde, intimamente relacionado à compreensão de que a saúde é dependente dos resultados de outros setores da ação governamental, dificuldade que, para ser vencida, requer o entendimento, a aceitação e a defesa do conceito ampliado de saúde, como expresso acima.

Desse modo, para intervir na realidade, é necessário que os setores da educação e da saúde estabeleçam uma estreita e permanente parceria interinstitucional, objetivando desenvolver ações conjuntas e articuladas para a elaboração e a construção de uma proposta educacional que conjugue os conhecimentos produzidos e acumulados pelas duas áreas. Sendo esse o sentido, é preciso que a proposta compartilhada se insira "em um projeto mais amplo de sociedade, de história humana e de ação política" (Frigotto, 1988, p.8), estabelecendo uma dinâmica que contemple a direcionalidade e as conseqüências, para o conjunto da sociedade, da incorporação e da aplicação de novas tecnologias.

É preciso, portanto, construir um processo educacional que articule a formação profissional com as necessidades e as demandas da sociedade, como estratégia eficaz para o desenvolvimento econômico, social e cultural dessa mesma sociedade, na perspectiva de possibilitar ao indivíduo o exercício eficiente de

\footnotetext{
${ }^{3}$ A respeito do assunto, consultar Torrez, 1994.
} 
seu trabalho, a participação consciente e crítica no mundo do trabalho e na esfera social, além de sua efetiva auto-realização. Isto requer clareza, vontade política e compreensão das dificuldades por parte dos dirigentes para que, sem confrontar abertamente com o arcabouço legal instituído mas, também, não se condicionando a ele de maneira absoluta e inquestionável, se desenvolva uma possibilidade política e pedagógica para o campo da formação profissional, com o sentido de repensar e de contribuir para redefinila mediante o abandono de uma prática educativa de cunho tecnicista, a-histórica e a-crítica, representando uma busca para situar o homem em sua realidade histórica. A parceria deverá consistir em um processo facilitador da simbiose entre trabalho, educação e saúde, procurando vencer a histórica dicotomia entre pensar e fazer, entre geral e específico, integrando habilidades teóricas e práticas.

A problemática da formação profissional perante uma realidade de mutações constantes remete, compulsoriamente, à reflexão sobre o modo como a sociedade se organiza e se conforma na relação entre dominantes e dominados, reflexão que deve sinalizar uma direção que não se contente apenas com o processo de aprendizagem em dado espaço e contexto, mas que tenha por horizonte uma sociedade transformada. Ou seja: uma reflexão comprometida com um projeto de sociedade, tendo o homem como prioridade essencial e centro das preocupações.

\section{Desafios da formação profissional em saúde}

Para viver e, sobretudo, sobreviver nesse cambiante mundo novo, faz-se necessário, ao homem, repensar sua forma de inserção e modos de participação na realidade que vem sendo moldada, construindo o futuro a partir da assimilação, da reflexão, do questionamento e formulação de propostas calcadas na realidade objetiva em que se insere, a partir da qual deverão ser elaboradas e implementadas estratégias políticas visando transformar essa mesma realidade.

Entre os requerimentos da dinâmica profissional, o trabalhador deve possuir capacidade de diagnóstico, de solucionar problemas, de tomar decisões, de intervir no processo de trabalho, de atuar em equipe, de auto-organizar-se. Como mencionado, é preciso pensar uma formação profissional orientada para o trabalho - entendido como processo de humanização do homem - que objetive integrar conhecimentos gerais e específicos, habilidades teóricas e práticas, hábitos, atitudes e valores éticos. A educação torna-se fundamental, portanto,

\footnotetext{
para que os indivíduos dominem as ciências (físicas, químicas e biológicas), as linguagens (a matemática, as línguas, a informática, as artes e a expressão corporal) e os estudos do homem (a história, a geografia, a sociologia, a economia e a filosofia) para que possam compreender e atuar no mundo social e cultural no qual estão inseridos. (Deluiz, 1997, p.17)
}

Além disso, torna-se necessário desenvolver as habilidades comunicativas (capacidade de expressão e de comunicação com seu grupo, superiores hierárquicos ou subordinados, cooperação, trabalho em equipe, diálogo, exercício da negociação), as capacidades sociais (capacidade de transferir conhecimentos da vida cotidiana para o ambiente de trabalho e vice-versa) e as habilidades comportamentais como iniciativa, criatividade, vontade de aprender, abertura às mudanças e consciência da qualidade e das implicações éticas do seu trabalho ${ }^{4}$. A aquisição, o domínio e a prática desse conjunto de saberes e de fazeres pelos trabalhadores da saúde é primordial para sustentar as ações e as atividades a serem implementadas para estruturar e dar seguimento a uma política cuja abrangência alcance as esferas federal, estadual e municipal da administração, que inclua os setores público e privado que compõem o Sistema Único de Saúde e que tenha entre suas prioridades a formação e a gestão de pessoas, bem como a regulação e a regulamentação do trabalho em saúde. A humanização e a qualidade no atendimento aos usuários dos

${ }^{4}$ Com relação ao tema, conferir Deluiz, 1998. 
serviços de saúde, a (re)negociação dos vínculos empregatícios dos trabalhadores do SUS, a reavaliação das modalidades de inserção de profissionais no sistema, a avaliação permanente das relações entre a saúde e as diferentes áreas e organismos com os quais existe interação, são questões cuja resolução estão afeitas, essencialmente, ao modo de pensar e a maneira de agir de cada profissional que atua ou que venha a atuar no setor saúde.

No processo de construção dessas capacidades e habilidades, é preciso propiciar uma formação que permita aos trabalhadores agir como cidadãos produtores de bens e de serviços e como atores na sociedade civil. Mais do que nunca, "a educação deve possibilitar aos trabalhadores (...) sua participação na sociedade científica e tecnológica não como objetos, mas como sujeitos, resgatando assim a dimensão política: a construção da identidade social e a integração plena na cidadania. (Deluiz, 1997, p.16)

Nessa ótica, o conceito de educação deve ser entendido como um compromisso com os ideais da sociedade e refere-se a um conjunto de práticas sociais, com os valores, crenças, atitudes, conhecimentos formais e informais que uma dada sociedade tende a desenvolver para preservar ou melhorar as condições e a qualidade de vida da população. Deve ser redimensionada como processo e produto social e como fator substantivo do desenvolvimento humano, firmado na interrelação de, pelo menos, cinco componentes básicos: educação, saúde, crescimento econômico, meio ambiente, o direito e o exercício pleno da cidadania.

Educar pessoas conscientes de seu papel social, com percepção macro dos problemas que afetam a humanidade, representa proporcionar a cada indivíduo a oportunidade de assumir e exercitar uma postura que alie, de modo simultâneo, despojamento e rebeldia. Despojamento no sentido de humildade suficiente para realizar a autocrítica em relação ao próprio desempenho, reconhecendo os limites para sua forma de agir; rebeldia no sentido de se dispor a questionar e enfrentar dogmas e barreiras socialmente impostas, revelar-se, enfim, na coragem de ousar. A cada um de nós compete o esforço de superar as próprias limitações de indivíduos historicamente construídos, numa sociedade que preza e impõe um existir fragmentado, parcializado e egoísta.

Nesse percurso, é necessário aprofundar a reflexão sobre os meios e os modos como a formação profissional vem ocorrendo, isto é, se os conteúdos curriculares e as metodologias de ensino utilizadas permitem ao aluno apreender tanto os procedimentos técnicos indispensáveis ao exercício profissional como, também, desenvolver visão crítica em relação ao processo de trabalho e ao mundo que o circunda. É preciso instituir estratégias que escapem a padrões convencionais de educação, como a implantação e o desenvolvimento, na esfera da educação profissional, de projetos dinamizadores do uso de novas tecnologias, promovendo e articulando o conhecimento produzido com as necessidades que (re)configuram a sociedade atual. Da mesma maneira, é imprescindível repensar o papel e a importância do professor, que necessita ser valorizado em sua profissão, o que inclui condições salariais e de trabalho condizentes com suas responsabilidades, com possibilidade de se manter atualizado e atento em relação às mudanças contemporâneas que vêm dando nova feição ao mundo. 


\section{ESPAÇO ABERTO}

\section{Referências}

BRASIL. Ministério da Saúde. 8ª Conferência Nacional de Saúde. Relatório final. Brasília/DF: Ministério da Saúde, 1986.

BRASIL. Ministério da Saúde. Relatório final. In: CONFERÈNCIA NACIONAL DE SAÚDE, 11., 2001, Brasília, DF. Anais... Brasília, DF, 2001. 198p.

DELUIZ, N. Formação do trabalhador: produtividade e cidadania. Rio de Janeiro: Shape, 1998.

DELUIZ, N. Neoliberalismo e educação: é possível uma educação que atenda os interesses dos trabalhadores? Tempo e Presença, n.293, mai./jun, p.14-6, 1997.

FRIGOTTO, G. Formação profissional no segundo grau: em busca do horizonte da educação politécnica. Rio de Janeiro: Ministério da Saúde/Fundação Oswaldo Cruz, 1988.

FRIGOTTO, G. Educação e a crise do capitalismo real. São Paulo: Cortez, 1995.

GIANNOTTI, J. A. O público e o privado. Folha de São Paulo. São Paulo, 2 abr. 1995.

HARDT, M.; NEGRI, A. Império. Rio de Janeiro: Editora Record, 2001.

OFFE, C. Trabalho e sociedade: problemas estruturais e perspectivas para o futuro da sociedade do trabalho. Tempo Universitário, v. 2, n.89, 1991. (Série Estudos Alemães)

TORREZ, M. N. F. B. Qualificação e trabalho em saúde - o desafio de "ir além" na formação dos trabalhadores de nível médio. 1994. Dissertação (Mestrado) - Faculdade de Educação, Universidade Federal do Rio de Janeiro, Rio de Janeiro.

UNIVERSIDADE FEDERAL DO RIO DE JANEIRO. Núcleo de Estudos de Saúde Coletiva. Centro de Ciências da Saúde. Curso de Graduação em Saúde Coletiva. Rio de Janeiro, 2003. (mimeogr.)

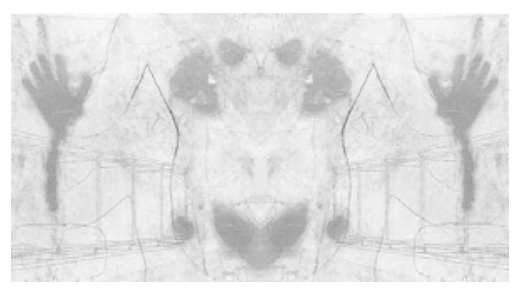

This article is a contribution to the debate on professional training for the health sector, considering the current context of internationalization of the economy and the integration of markets, where scientific progress produces significant changes in social relationships and in the production of goods and services. It emphasizes the need to establish a permanent partnership between the health and education sectors with the aim of putting together a political and pedagogical proposal that allows health workers to acquire and master diversified competences, which enable them to understand, to act and to face, in critical way, the changes that have been occurring in the world of work. KEYWORDS: Education in health; work; professional education.

O artigo insere-se na discussão sobre a formação profissional em saúde, em um contexto marcado pela internacionalização da economia e pela integração de mercados, em que os avanços científicos promovem significativas mudanças nas relações sociais e de produção de bens e de serviços. Enfatiza-se a necessidade de se estabelecer uma parceria permanente entre os setores educacional e da saúde, visando elaborar uma proposta política e pedagógica que permita aos trabalhadores da saúde a aquisição e o domínio de diversificadas competências, habilitando-os a compreender, atuar e enfrentar, de modo crítico, as mudanças que vêm se processando no mundo do trabalho.

PALAVRAS-CHAVE: Educação em saúde; trabalho; formação profissional.

Este artículo es una contribución a la discusión acerca de la formación profesional en el sector de salud, en un contexto marcado por la internacionalización de la economía y por la integración de mercados, donde los progresos científicos promueven cambios significativos en las relaciones sociales y en la producción de mercancías y de servicios. Se enfatiza la necesidad de establecer una alianza permanente entre los sectores de educación y salud para construir una propuesta política y pedagógica que permita que los profesionales del sector de salud adquieran y dominen diversas competencias, las cuales les permitirán entender, actuar y hacer frente, de manera crítica, a los cambios que están procesándose en el mundo del trabajo. PALABRAS-CLAVE: Educación en salud; trabajo; formación profesional. 